\title{
The societal "surprise factor": Nuclear and greenhouse hazards and the ethics of good policy development
}

\author{
A. Henderson-Sellers
}

\author{
ANSTO Environment, PMB 1, 2234 Menai, Australia
}

\begin{abstract}
It is arguable that one of the many triggers for the Tokaimura nuclear accident in Japan in September 1999 was the agreement by the Framework Convention on Climate Change member nations to the Kyoto Protocol on greenhouse gas emissions reductions, also in Japan in December 1997. Whether or not the Kyoto Protocol is finally ratified there is increasing pressure on all developed nations to quantify and act to reduce or off-set their greenhouse gas emissions. For Japan where power generation from fossil fuels is already very efficient and there is relatively little available land on which to plant forests to become carbon sinks this international treaty must increase the aftractiveness of nuclear power. In all nations policies must be developed to try to mitigate and adapt to the consequences of both global warming and nuclear hazards. The attitude of the general public to the risks of both is a critical ingredient in the development of these policies. Both greenhouse warming and nuclear science depend on physics which can be difficult to understand and both are therefore open to media (and other) misinterpretation accidental and intentional. Greenhouse \& nuclear management are subject to real \& predicted 'surptises' which greatly increase the sense of alarm amongst the public and politicians. This paper explores some of the societal \& ethical aspects of this "surprise factor" for greenhouse and nuclear policy development and touches on tricky aspects of national policics which link nuclear \& climate science through their consequences (c.g. "safe" repositories for nuclear waste affected by greenhouse-induced climate change) as well as their origins (e.g. nuclear replacing fossil fuel power generation).
\end{abstract}

\section{NUCLEAR AND GREENHOUSE HAZARDS IN THE GLOBAL VILLAGE}

Nuclear hazards are no longer perceived as bombs or the threat of a planet-wide "nuclear winter". These days, most public policy issues relating to nuclear hazards pertain to either (i) the environmental and human impacts of nuclear generator accidents or (ii) the environmental and human impacts of nuclear waste transfer and storage. At the beginning of the twenty-first century, nuclear hazards of importance to society can be described as environmental radiotoxicological. Greenhouse hazards are generally percejved to be related to persistent changes in local weather and also to global geophysical phenomena such as sea-level rise and ice cap diminution. They are seen to be primarily environmental but also recognised as affecting people as a result of extreme events such as storms, heat waves, droughts and floods. The impacts of greenhouse warming are generally environmental and physiological rather than toxicological.

Geopolitical arguments about both types of hazards abound. If it is agreed that the North is imposing hardships on the South as a result of over a century of greenhouse emissions, there may be an obligation on the emitting nations to rectify this inequity. The legal case has been tested and found to depend on how international rights, liabilities and obligations are interpreted. Although Stockholm and other international law principles of responsibility set out the rights of the victim states, common law practice so far seems to suggest that these rights do not yet exist in intemational legal practice. Some states have accepted liability for transborder damages, for example, the Soviets in the case of the Cosmos 984 and the USA and Canada with regard to acid rain. On the other hand, after Chernobyl, Germany's and other nations" requests for compensation were tumed down by the then USSR. Thus the legal framework in which responsibility for greenhouse and nuclear hazard mitigation and compensation may be adjudicated is similar, or maybe the same, and, as yet, very poorly developed. 
The base cause of both greenhouse and tomorrow's nuclear hazards is the growing global demand for energy: a demand likened to addiction (Table 1). Recent greenhouse gas increases are due primarily to the increased burning of fossil fuel (e.g. carbon dioxide); industrial processes (e.g. chlorofluorocarbons); and intensification of agriculture (e.g. methane). Most people appreciate that rapidly increasing demands for power underpin the growth both in fossil fuel exploitation and in nuclear power developments. At the beginning of the twenty-first century, it is appreciated that reduction in fossil fuel use must, almost inevitably, lead to increases in nuclear power plants. Unless humanity as a whole can set aside its addiction to energy, it seems likely that nuclear and greenhouse hazards will persist in our environment, will cause 'surprises' and, hence, will come under increasing public policy scrutiny.

Equity debates about greenhouse and nuclear hazards and can be most clearly discerned in Europe, which traditionally employs classical utilitarian arguments in public policy justifications. European policies tend to appeal to global responsibility rather than to global efficiency, invoking equity arguments about stewardship (e.g. the care and preservation of local and global commons) for current and future generations. This type of appeal seems to presuppose a concept of global management or even, perhaps, global governance, which does not, and may never, exist.

Table 1 Nuclear and greenhouse hazards both arise from societal demand for energy which is highly addictive.

\begin{tabular}{|l|l|}
\hline \multicolumn{1}{|c|}{ Clinical stages of addiction } & \multicolumn{1}{c|}{ Observed symptoms of global energy addiction } \\
\hline Tolerance & - reduced effect from the same energy input (dose) \\
\hline Withdrawal response & - disagreeable felings when (drug) energy is denied \\
\hline Relief on reinstatement & - pleasure/reassurance when (drug) energy is returned \\
\hline Compulsion & - craving for (drug) energy \\
\hline Narrowing of behavioural repertoire & - energy (drug) dependent stereotypical behaviours \\
\hline Salience & - increased priority given to energy (drug) despite known negative consequences \\
\hline Re-instatement after abstinence & - rapid retum to dependence when energy (drug) used \\
\hline
\end{tabular}

\section{NUCLEAR AND GERENHOUSE HAZARDS: SIMILARITIES AND LINKS}

The first, most obvious and most widely neglected link between greenhouse and nuclear hazards is that both arise as a result of societal demand for energy (Table 1). Other similarities between greenhouse and nuclear hazards include unfamiliar terminology and units; government regulation; and mass media coverage obscured by both these former attributes (Table 2). Another very important characteristic of these hazard sets is the long time periods they span. Radiotoxicology is perceived to persist for hundreds of years, at least and the consequences of greenhouse warming are similarly seen to be particularly harmful a hundred or more years from now. Thus, both nuclear and greenhouse hazards share the characteristics of being "in the future" and thus of importance to grandchildren of today's voters and policy makers and their progeny. This longevity of impact and/or consequences tends to confuse standard risk management strategies. Public and political opinion is widely divided on how best to respond to an extreme or even catastrophic consequence predicted to be very likely but occurring at some future time two or three generations distant.

Table 2 Similarities between nuclear and greenhouse hazards and policies to manage them

\begin{tabular}{|l|l|}
\hline Energy & - both caused. at root. by insatiable demands for energy \\
\hline Time delay & - both produce effects hundreds of years in the future affecting grandehildren and their progeny \\
\hline Confusing & -both described in terms of unfamiliar terminology and using difficult units \\
\hline Government & - both caused by and regulated by governments i.e. out of the hands of citizens \\
\hline Media & - both 'debated' in the mass media, often in terms of extreme events and ethics \\
\hline Uncertainty & - both are portrayed in terms of risks and uncertainties which form the basis of possible surprises \\
\hline Equity & $\begin{array}{l}\text { - both are beset by complex arguments pertaining to the perceived faimess/unfairness of hazard } \\
\text { management and minimization }\end{array}$ \\
\hline
\end{tabular}

Interestingly, at least to my mind, this longterm consequence characteristic divides rather than unites greenhouse and nuclear hazards. By this, I mean that people who oppose nuclear power, nuclear waste 
storage facilities and the transfer of nuclear wastes do so often on the basis of the long-term impacts. In contrast, action to reduce greenhouse gas emissions is being opposed, or at least resisted, precisely because the impacts will occur many years in the future and, it is argued, perhaps there will by then be cheaper response strategies which will effectively alleviate the consequences and so reduce the overall risk. The time value of money is critical to such complex debates but even considered simplistically the economics of greenhouse gas abatement seem to be questionable. For example, Schelling [1] (p13) asks: "Is there something escapist about discussing $2 \%$ of GNP to be invested in the welfare of future generations, when we do nothing like that for their contemporary ancestors, a third of whom are so undernourished that even a case of measles can kill them?"

The issue of equity or "faimess" is very complex. Relatively few citizens today subscribe to the Aristotelian principle that states that public goods (and wastes) should be distributed to each contributor in strict proportion to their contribution. Even egalitarian viewpoints do not always argue for strict equality. If this were society's view, then global warming would be almost solely the responsibility of the 'developed' nations and there would be no possibility for US Republicans to demand inclusion of the developing nations in the Kyoto Protocol. Many people and nations increasingly argue in favour of redressing past inequities. In terms of greenhouse, this may mean disadvantaging the wealthy countries on the basis of their historical contribution [2]. For hazardous waste facilities, it could involve location in wealthy neighbourhoods because the wealthy are perceived as having contributed more to the waste problem by their larger consumption e.g. [3]. The idea of valuing damages less in the poor countries is objectionable, at best. Many people vehemently objected to the IPCC [4] Second Assessment Report's placing of a lower value on a Jife in poor countries than rich despite standard actuarial practice. Jaworski [5] asks rhetorically how we justify the estimated costs of $\$ 2.5$ billion for each human life saved by radiation protection regulations when saving people from dying of measles costs only $\$ 50$.

Confusing terminology is a serious issue for both greenhouse and nuclear policy developers. Indeed, it is not unknown for politicians and the public to entangle the two sets of terms and, for example, describe greenhouse as "radiation waming". Deeper complexities surround units of doses and exposures in nuclear and radiological science and comparative warming potentials of different gases in greenhouse treatises. Such confusion is responsible, in part, for the, sometimes negative, role played by the mass media in public debate and hence public policy e.g. [6]. A press 'beat-up' of issues of, reasonable, public concern is decried by scientists while being a shon fuse for many politicians e.g. [7].

Negative outcomes arising from nuclear and greenhouse events also share many characteristics: i) impossibility of ever retuming to pre-event conditions; ii) effects impacting people not involved in the generation of, or receiving the benefits from, the cause of detriment; and iii) post-event trauma including economic repercussions. Public policy options to mitigate such hazards must involve equitable, and accepted, decision-making mechanisms, widespread participation and community control of outcomes, at least to some demonstrable degree. Such multi-faceted policy development is complicated in modern divergent, democratic societies which themselves take different views of issues of equity. Most European nations have enacted stringent legislation against exporting wastes out of the country in favour of a larger state role in their management e.g. [8]. In contrast, the US, with its more individualistic culture, has been reluctant to enter agreements limiting international trade in wastes. Both Australian and US negotiators at Kyoto justified their arguments for smaller commitments in greenhouse gas reductions than Europe's on the grounds that their nations were expecting greater economic growth and thus would need higher emissions. Australians also claimed that smaller overall emissions would arise if fossil fuel intensive operations such as aluminium smelting were to remain in their economy rather than move to other countries where dirtier technology was used.

\section{THE PARADOX OF UNCERTAINTY IN NUCLEAR AND GREENHOUSE HAZARDS}

The scientific basis for nuclear waste shipment and storage and for radioecological clean ups are well understood. Similarly, the global greenhouse is founded on over a hundred years of atmospheric physics [9]. Neither hazards draw on recent scientific discoveries, instead depending only upon well described and well known science that is now taught in schools and depicted in TV documentaries and news items. 
The science of nuclear management and greenhouse warming is not 'cutting edge' research comparable to, for example, the searches for a cure for cancer or a vaccine against HIV/AIDS.

Despite these facts, both nuclear waste/clean-ups and global warming are perceived to be beset by uncertainties. This perception is very widespread including many scientists as well as the vast majority of the lay public, politicians and policy developers. This "paradox of uncertainty" which pervades almost all debate about greenhouse and nuclear hazards seems to be derived from society's proclaimed fear of surprises and concem about future retribution. Some nations have already enacted post facto legislation so that people and organizations which legally disposed of hazardous wastes in the past and without knowledge of the consequences and are now being held liable for cleanup and punitive damages.

Issues surrounding societal surprise can be summarized in the following three quotations: "a surprise is only a surprise if it is noticed by the holder of the beliefs that it contradicts" [10] "since surprise is inevitable, we should strive to make (public) policy that accounts for it" [11]; and "surprises are sometimes searched for and manufactured" [12]. The first quotation is definitional and advises us that if we could instil in the general public, or even our fellow scientists, our current understanding of nuclear and greenhouse issues, the propensity for surprises could be very greatly reduced. The Saleska quotation follows by underlining the obvious truism that surprise cannot be predicted and hence must be allowed for in some other way. Finally, Kasperson underlines the role played by the mass media's treatment of nuclear and greenhouse topics. 'Surprises' are thrust into media 'debates' often without definition and almost always without adequate explanation or examination. This searching out, or even invention, of 'surprises' in discussions of both nuclear and greenhouse hazards can greatly confuse policy issues relating to uncertainty and perceived faimess and unfaimess.

Table 3 Types of surprises and societal responses (modified from Kates and Clark [13], p29)

\begin{tabular}{|l|l|l|}
\hline \multicolumn{2}{|c|}{ Surprise type } & \multicolumn{1}{|c|}{ Surprising Events/Consequences/Causes } \\
\hline $\begin{array}{l}\text { I. Rare event, serious } \\
\text { consequences }\end{array}$ & $\begin{array}{l}\text { Bhopal; Seveso; Chernobyl } \\
\text { Three Mile Island; Mount St Helens }\end{array}$ & $\begin{array}{l}\text { Emergency response to reduce } \\
\text { consequences }\end{array}$ \\
\hline $\begin{array}{l}\text { 2. Common event eluding } \\
\text { detection or prediction }\end{array}$ & $\begin{array}{l}\text { Legionnaircs disease; Lyme disease } \\
\text { Radon gas in homes; Food poisoning outbreaks }\end{array}$ & $\begin{array}{l}\text { Screening and monitoring for earlier } \\
\text { detection }\end{array}$ \\
\hline $\begin{array}{l}\text { 3. Unexpected consequences } \\
\text { from deliberate acts }\end{array}$ & $\begin{array}{l}\text { CFCs; Lead in paint and petrol; Asbestos fibres; } \\
\text { Secondary cigarette smoking }\end{array}$ & $\begin{array}{l}\text { Modes of analysis to consider the } \\
\text { unthinkable }\end{array}$ \\
\hline $\begin{array}{l}\text { 4. Expected but mistakenly } \\
\text { attributed outcomes }\end{array}$ & $\begin{array}{l}\text { Stratospheric ozone depletion } \\
\text { Ground-level ozone damage; Forest damage }\end{array}$ & $\begin{array}{l}\text { Modes of analysis that emphasize } \\
\text { multiple and unknown causation }\end{array}$ \\
\hline
\end{tabular}

Table 3 links 'surprise' to concepts of risk assessment and management response strategies. Two nuclear accidents figures in the first surprise type and that natural radionuclides (radon and its progeny) appear in the second. Greenhouse is a secondary outcome in the third type because of its contribution to global warming while, in surprise type 4, recent research has shown that although CFCs are the primary cause of the "ozone hole". greenhouse warming is, paradoxically, also causing stratospheric cooling and hence contributing conditions which facilitate and enhance stratospheric ozone removal. Policy development is encumbered by society's current management process and especially in relation to surprises. Apparent underestimation of our understanding of systems tends to encourage the perpetuation of the status quo and Kasperson [12] argues that this is management failure to be redressed by expansion of uncertainty bounds. Arguably, it may be even more important for scientists to stafe uncertainty bounds (e.g. Table 4).

\section{GOOD POLICIES DEMAND SOCIETY'S TRUST}

The UK House of Lords Report on 'Science and Society' [14] identifies a wide variety of reasons for public lack of trust in science including: the purpose (perceived or actual) of science is unimportant; people now question all (including scientific) authority; people feel reduced trust for science which is not seen as "independent"; any culture of governmental and institutional secrecy invites suspicion; excluding moral, social, ethical and other concems from public problems and describing them solely as 
"science" angers people; and public acceptability tends to relate to the control felt and ability to make choices and hence often fails to correspond with the objective risks as stated by science.

Table 4 Uncertainties in observed and predicted extreme weather and climate events arising from greenhouse warming (after Houghton et al. [15], p15)

\begin{tabular}{|c|c|c|}
\hline $\begin{array}{l}\text { Confidence in observed changes } \\
\text { (latter half of the 20th century) }\end{array}$ & $\begin{array}{c}\text { Changes in phenomenon duc to } \\
\text { greenhouse }\end{array}$ & $\begin{array}{l}\text { Confidence in projected changes } \\
\text { (during the } 21 \text { st century) }\end{array}$ \\
\hline Very likely & $\begin{array}{l}\text { Higher minimum temperatures, fewer } \\
\text { cold days and frost days over nearly all } \\
\text { land areas }\end{array}$ & Very likely \\
\hline Very likely & $\begin{array}{l}\text { Reduced diurnal temperature range } \\
\text { over most land areas }\end{array}$ & Very likely \\
\hline Likely & $\begin{array}{l}\text { Higher maximum temperatures and } \\
\text { more hot days over nearly all land areas }\end{array}$ & Very likely \\
\hline Likely, over many areas & Increase of heat index over land areas & Very likely, over most areas \\
\hline $\begin{array}{l}\text { Likely, over many Northern } \\
\text { Hemisphere mid- to high latitude land }\end{array}$ & More intense precipitation events & Very likely, over many areas \\
\hline Likely, in a few areas & $\begin{array}{l}\text { Incressed summer continental drying } \\
\text { and associated risk of drought }\end{array}$ & $\begin{array}{l}\text { Likely, over most mid-latitude } \\
\text { continental interiors. }\end{array}$ \\
\hline $\begin{array}{l}\text { Not observed in the few analyses } \\
\text { available }\end{array}$ & $\begin{array}{l}\text { Increased tropical cyclone peak wind } \\
\text { intensities }\end{array}$ & Likely, over some areas \\
\hline Insufficient data for assessment & $\begin{array}{l}\text { Increased tropical cyclone mean and } \\
\text { penk precipitation intensities }\end{array}$ & Likely, over some areas \\
\hline
\end{tabular}

Negative attitudes are a necessary but by far not a sufficient reason for behavioural responses. Public confidence, or rather its lack, in institutional performance is another and even more important element in triggering behavioural responses. The slightest mistake by a risk management agency can be sufficient to destroy the delicate balance of societal trust. The handling of risk by government agencies and private corporations has been the trigger for mobilization by individuals taking, usually negative, actions. The more strongly citizens come to believe that risks are not properly handled, especially when they are aiso perceived as serious threats, the greater is the likelihood that people will become politically active. In the case of nuclear power, the disillusionment of German and other voters with the nuclear option as well as the number of people becoming political advocates of antinuclear policies has grown along with increasing distrust in nuclear regulatory agencies.

The difficulties of meshing science with public perception have been described for many years. Famously, Immanuel Kant stated: "Concepts without perceptions are empty; perceptions without concepts are blind. Science provides the vision for otherwise blind, perception-based action." Rephrasing into a modern risk management jargon gives: "the perceived risk should be based on scientifically estimated risk" but how best to accomplish this is challenging. The U.K. House of Lords report concludes that "Underlying people's attitudes to science are a variety of values. Bringing these into the debate and reconciling them are challenges for the policy maker" [14] (p5). Both greenhouse policy and nuclear hazard management are prey to public nervousness. Specifically, many green groups are nervous about joint actions by government and industry. For example, the negative reaction to Al Gore's post-Kyoto announcement of a new partnership between the electronics industry and the Environmental Protection Agency which was perceived to be divergent from his 1992 'Earth in the Balance' [16]. Public attitudes towards the management of nuclear waste were found by the House of Lords Select Committee on Science and Technology [17] to depend upon: (i) factors which heighten public concern about risk such as lack of personal control, difficulty of setting risk against benefit, special "dread factors" and unacknowledged or understated uncertainty; (ii) difficulties of numerical risk assessment; (iii) complexity of public attitudes and their capacity to change, particularly when subjected to media coverage; (iv) NIMBYism i.e. people's capacity to accept something in general, and yet object when it threatens to touch them directly; and $(v)$ the capacity of those in authority to misread public attitudes and misunderstand the importance of public trust in institutions. Similarly, Nicholls [18] bemoaned the lack of studies aimed at identifying why potential users were not incorporating climate predictions in the decision-making processes. He comments that Changnon et al. [19] surveyed decision 
makers in the US power utilities, specifically to try to discern the needs and uses of climate forecasts. They found less than $6 \%$ of the decision makers surveyed had used forecasts. Major hindrances to the use of forecasts were said to include the following: "forecasts difficult to interpret, lack of models to integrate information, uncertainty over accuracy, additional information necessary, proof of value necessary, lack of access to expertise, difficult to assess forecasts" [18] (p1385).

These various assessments seem to point to commonalities between greenhouse and nuclear hazards including: (i) the failure of the public to perceive the source of the hazards as arising from a benefit (energy) which they derive and wish to maintain; (ii) "sanitised science" i.e. scientific evaluations perceived to be isolated from moral, social and ethic issues and values and a failure to bring science to underpin societal risk assessment; (iii) difficulties with concepts, terminology, units, numerics of evaluation; (iv) the lack of public confidence in government organisations especially when they appear compromised, lack independence, or have the dual role of hazard generator and hazard regulator; and ( $v$ ) media coverage which emphasises uncertainties, dreads and potential for 'surprises'. In both the greenhouse and nuclear contexts, public suspicion and fear seems to be growing rather than diminishing with time. In order to reduce this negativity it will be necessary for public policy to, at least, address these first three points by improving education and consider tactics to try to alleviate the impacts of the latter two points by, perhaps, establishing independent regulators and advisers.

\section{References}

[1] T.C. Schelling, Foreign Affairs, 76(6), 8 (1997)

[2] A. Grubler, Y.Fujji, Energy, 16, 1397 (1991)

[3] J. Linnerooth-Bayer, K. Fitzgerald, Risk: Health, Safety \& Environment, 7, 109 (1996)

[4] D.W. Pearce, W.R. Cline, A.N. Achanta, S. Fajkhauser, R. K. Pachauri, R.S.J. Tol, P. Vellinga, in The Second Assessment Report of Working Group III (Cambridge University Press, Cambridge,1996)

[5] Z. Jaworsk:, Physics Today, Sept 1999, 24 (1999)

[6] A. Henderson-Sellers, Climatic Change, 40, 421 (1998)

[7] S. Dunwoody, IEEE Trans. Prof. Comm. PC-25(4), 196 (1982)

[8] J. Linnerooth-Bayer, B. Davy, Report to the Bundesministerium Fuer Wissenschaft und Forschung, IIASA Contract No. 93-105, International Institute for Applied Systems Analysis, Laxenburg, Austria (1994)

[9] M.D.H. Jones, A. Henderson-Sellers, Progress in Physical Geography, 14, 1 (1990)

[10] M. Thompson, in Sustainable Development of the Biosphere (eds. W.C. Clark and R.E. Munn)

(Cambridge University Press, Cambridge, 1986)

[11] S. Saleska, in Elements of Change 1994, Part 2 (eds. S.J. Hassol and J. Katzenberger), Aspen Global Change Institute, Aspen, Colo., USA, 178 (1995) (1994)

[12] R. Kasperson, in Elements of Change 1994, Part 2 (eds. S.J. Hassol and J. Katzenberger), Aspen

Global Change Institute, Aspen, Colo., USA, 162 (1995)

[13] R.W. Kates, W.C. Clark, Environment, Marcy 1996, 6 and 28 (1996)

[14] HMSO, HL Paper 38, Select Committee on Science and Technology, Session 1999-2000 3rd Report (2000)

[15] J.T. Houghton et al., The Science of Climate Change, Third assessment report of the International Panel on Climate Change (Cambridge University Press, Cambridge, 2001)

[16] A. Gore, Earth in the Balance (Houghton Mifflin, USA, 1992)

[17] HMSO, House of Lords Select Committee on Science and Technology, Third Report, Management of Nuclear Waste (1999)

[18] N. Nicholls. Bull. Amer. Meteor. Soc., 80, 1385 (1999)

[19] S.A. Changnon, J.M. Changnon, D. Changnon, Bull. Amer. Meteor. Soc., 76, 711 (1995) 